\title{
Formal Safety Assessment on Current Inland Navigation Practices at Kenyir Lake, Malaysia.
}

\author{
Noor Apandi Osnin ${ }^{1, a}$ and Noorul Shaiful Fitri Abdul Rahman ${ }^{2, b}$ \\ ${ }^{1}$ School of Ocean Engineering, Universiti Malaysia Terengganu, Terengganu, Malaysia \\ ${ }^{2}$ School of Maritime Business and Management, Universiti Malaysia Terengganu, Terengganu, \\ Malaysia \\ a.apandi@umt.edu.my,b.nsfitri@umt.edu.my
}

Keywords: : Formal Safety Assessment, Kenyir Lake, Navigation Safety, Analytical Hierarchy Process, Inland Navigation.

Abstract: Kenyir Lake, Malaysia is a major tourist destination catering to almost a million visitors annually, the majority of whom are engaged in water-based activity and navigation. The formal safety assessment method (FSA) was introduced by the International Maritime Organisation as a tool for decision-making process to ensure that action is taken before a disaster occurs. It will be adapted and applied in conjunction with pair wise comparison method and community survey. The objective is to determine the status of current navigation practices on Kenyir Lake, identify hazards and propose counter measure to enhance navigational safety. The study found that capsizing is the main Hazard and that standard operating procedures have high benefit cost ratio as a Control Option. Local authorities could consider these in their approach to enhance navigational safety practices on Kenyir Lake especially for tourism management and economic sustainability. Inland navigation in general will benefit from the application of FSA on navigation practices.

\section{Introduction}

The regulatory framework for navigation is historically reactionary in nature. It exists in reaction to calamities experienced by the shipping community. The Lloyd's Register of Shipping Casualty Returns for 1958, the year before the International Maritime Organisation (IMO) was established show substantial losses from collisions, groundings and striking wrecks. A year later, in 1959, IMO begins introducing various measures in the forms of conventions, recommendations and other instruments towards the improvement of navigational safety [1]. Kenyir Lake, Malaysia is the largest artificial lake in South East Asia that was created primarily for power generation in 1985, due to its natural and man-made features result in a multi-use lake involving navigation. There is heavy involvement on lake use either for mode of transport, leisure activities or for income generation [2]. In reference to [1], these measures are applicable only to ocean going vessels. There is currently no unified regulatory framework for navigation in inland waters. Inland waters, rivers and lakes, are subject to the total sovereignty of the country as much as if they were an actual part of its land territory [3]. Based on observations, expert opinion and community survey it was established that the use of boats and navigation play a significant role on Kenyir Lake. 
There exists a gap on navigational safety for lake users in terms of standards and conventional navigation system compared to the current navigation practices being applied on the Lake [4].

In cognizance to [4], the study applies FSA to identify hazards of navigation on Kenyir Lake and propose control options to reduce frequency, alleviate circumstances or mitigate the consequence of navigational calamities.

\section{Literature Review}

Kenyir Lake is located about $55 \mathrm{~km}$ from Kuala Terengganu, the capital for the state of Terengganu, Malaysia. There are 49 villages populated by 16,119 locals and 334 aboriginals of the Semaq Beri and Batek tribe. The locals and aboriginals of Kenyir engages in navigation for fishing for food, hunting and forest product gathering around the lake, however their number are small compared to those for tourism [2]. 706,223 tourists were recorded for 2015 which are made up of primarily local visitors with about 10 percent international tourist. The numbers of users especially tourist, keep increasing as highlighted by record of tourist arrival in Figure 1 [5].

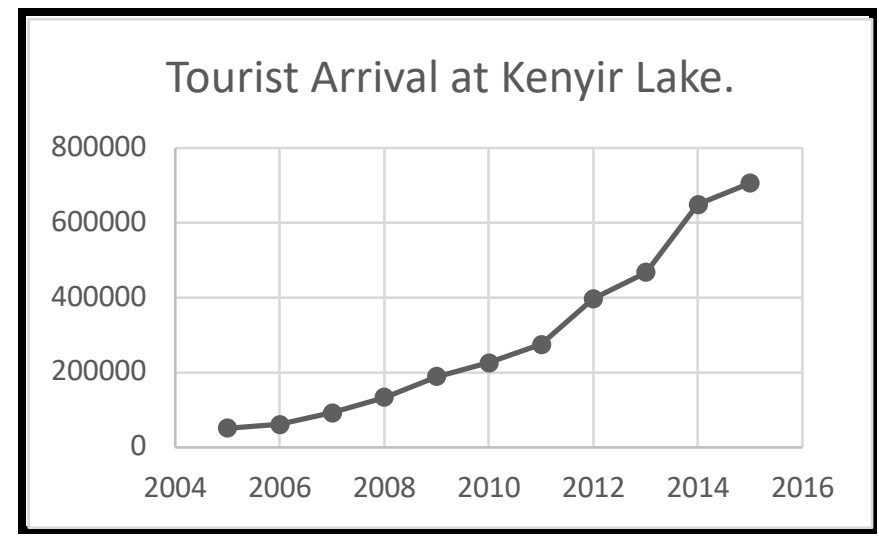

Figure 1: Tourist Arrival Kenyir Lake. Source: KETENGAH, 2016.

Figure 2 provides the number of tourist to Kenyir Lake in terms of economic contribution valued in Ringgit Malaysia (RM) based on data provided by the Terengganu State Economic Planning Unit (UPEN) [6].

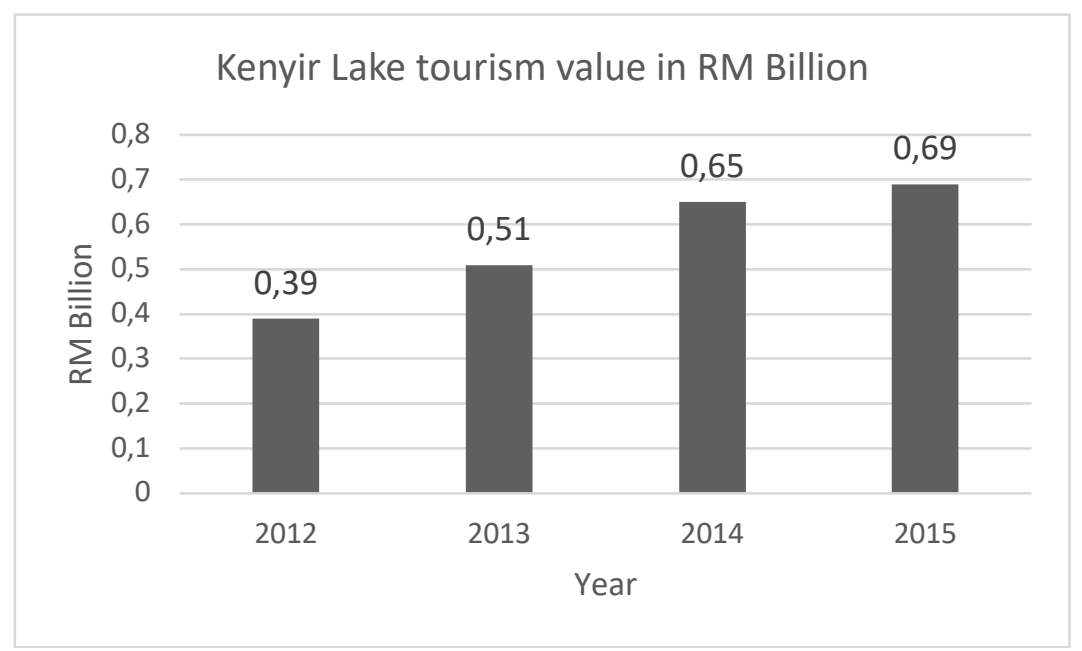

Figure 2: Economic contribution of Kenyir Lake tourism. Source: UPEN, 2016. 
Apart from tourist, local and aboriginal users, there are also business or industry user on Kenyir Lake that involves navigation, namely fish farming and logging activities and vessels used for enforcement by the authority.

Primarily, two types of vessels are used on Kenyir Lake, speed boats and house boats which caters to the tourism sector. The local and aboriginals typically use boats about 15 feet in length powered by either a 15 or 30 horse power engine while the speedboats used for tourists are up to 24 feet in length with more powerful engines. Houseboats are the largest water craft on Kenyir Lake between 60 to 85 feet in length and up to 30 feet wide. Based on MDHT's records, there are 200 registered boat, however it was also acknowledged that there are unregistered boats plying the lake [7], Table 1.

Table 1: Number Of Boats On Kenyir Lake

\begin{tabular}{|c|c|}
\hline Item & Number \\
\hline Registered boats & 200 \\
\hline Unregistered local boats* & 20 \\
\hline Unregistered aboriginal boats* & 20 \\
\hline Others i.e. barges, government crafts* & 20 \\
\hline Estimated Total & $\mathbf{2 6 0}$ \\
\hline
\end{tabular}

Source: MDHT, 2018.

Current navigation practices are based on basic human faculties that is by sight and hearing. This results in a built-in constraint as travel over water can only be done during daylight hours and navigating the lake requires local knowledge. There are signboards erected by the authorities to show distance and direction in general but no proper aids to navigation exists. In 2016, the local authority deployed 70 buoys about 1.2 meters high, equipped with solar powered blinking lights and are anchored in position using weights and rope. They are deployed in high traffic areas marking popular routes. However, these buoys are not compliant to international standards and conventions that are applied elsewhere in Malaysia [8].

Therefore, there is a need to assess the situation at Kenyir Lake with respect to movement over water and navigation due to an ever-increasing number of users which includes international tourists, and boats plying on the lake. This study will be based on IMO's FSA method to evaluate current navigational practices for Kenyir Lake towards maritime safety and protection of the marine environment and propose risk control options with a view to achieving a balance between the various technical and operational issues.

\section{Methodology}

The FSA method was introduced by the IMO in 1997, originally developed partly as a response the Piper Alpha disaster of 1988, when an offshore platform exploded in the North Sea causing 167 people to lose their lives. FSA is described as a structured and systematic methodology for rule making, aimed at enhancing maritime safety, including safety of life, health and protection of marine environment and property, by using risk analysis and cost-benefit assessment. FSA provides insight into the risk involved and potential mechanisms and strategies for risk control. It can be used to identify priorities and areas of concern and to analyse the benefits and implications of proposed changes [9]. This study applies IMO's formal safety assessment method on the current navigation practices at Kenyir Lake, Malaysia as outlined in Table 2. 
Table 2: Stepwise Process of the FSA Method

\begin{tabular}{|c|c|c|}
\hline \multicolumn{3}{|c|}{ Formal Safety Assessment Method } \\
\hline Step 1 & What might go wrong? & Hazard identification. \\
\hline Step 2 & How often, how likely? How bad? & $\begin{array}{c}\text { Risk analysis, Frequencies, Probabilities, } \\
\text { Consequences. }\end{array}$ \\
\hline Step 3 & How can matters be improved? & Risk control options identification. \\
\hline Step 4 & How much? & Cost benefit analysis. \\
\hline Step 5 & What actions should be taken? & Recommendations. \\
\hline
\end{tabular}

Source: IMO, 2002

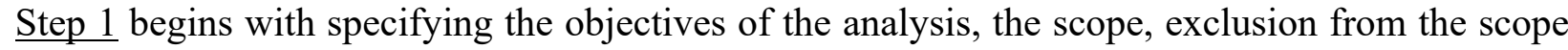
and limitations if any. Hazard identification (HAZID) for this study is a qualitative exercise based primarily on expert judgement grounded on a list culled from literature review followed by consultation with group of experts to identify the hazards that are prevalent with navigation on Kenyir Lake [10]. The purpose is to identify all potential hazards including causes and effects, rank hazards by their risk to focus further analysis on relevant risk contributors and provide information for identification of risk reducing measures [9]. For this study, the experts engaged would include representative from local authority, enforcement agency, boat owners and navigators, Table 3 . Ten expert respondents were selected, each having at least five years' experience operating on Kenyir Lake or in similar capacity elsewhere. This is because there is a tendency for government servants to be transferred after a period of time and also because Kenyir Lake is relatively new and tourism arrival only breached the 100,000 marks as late as 2008 .

Table 3: Expert Consultation on Hazards, Kenyir Lake

\begin{tabular}{|c|c|c|c|}
\hline Expert & Sector & Position & Experience \\
\hline 1 & KETENGAH & Management & $>5$ years. \\
\hline 2 & KETENGAH & Enforcement & $>5$ years. \\
\hline 3 & MDHT & Management & $>5$ years. \\
\hline 4 & Marine Police & Enforcement & $>5$ years. \\
\hline 5 & TNB Berhad, Kenyir & Safety Ops. & $>5$ years. \\
\hline 6 & Navigator & Helmsman & $>5$ years. \\
\hline 7 & Navigator & Helmsman & $>5$ years. \\
\hline 8 & Navigator & Helmsman & $>5$ years. \\
\hline 9 & Boat owner & Businessman & $>5$ years. \\
\hline 10 & Boat owner & Businessman & $>5$ years. \\
\hline
\end{tabular}

Step 2, risk analysis is used to estimate risk for ranking based on frequency and consequence. Prioritized list of hazards including description of their causes, description of consequences, estimations of frequency and consequence, risk ranking [11]. An analytical hierarchy process (AHP) technique is used to develop a scientific model using mathematical algorithm calculation followed by pair-wise comparison approach to determine the weight value of each criteria [12]. The AHP approach is a proven technique that is well suited for organising and analysing complex decisions involving both quantitative and qualitative data. It is based on the well-defined mathematical structure of consistent matrices and their associated right eigenvector's ability to generate true or approximate weights [13]. More importantly, it enables comparison of criteria or alternatives with respect to a criterion in the form of pair-wise comparison mode. The weight values obtained in the pair-wise comparison matrix are checked for consistency using a Consistency Ratio (CR) formula: 


$$
C R=\frac{C I}{R I}
$$

Where $C I$ stands for consistency index and $R I$ is the Random Consistency Index. The CR is designed in such a way that a value greater than 0.10 indicates an inconsistency in pair-wise comparison. If $\mathrm{CR}$ is 0.10 or less, the consistency of the pair-wise comparisons is considered reasonable [14].

$\underline{\text { Step } 3}$, risk control option (RCO) for this study is a qualitative exercise based primarily on expert judgement to propose counter measures in response to outcome of Step 2 for Kenyir Lake. The proposed RCO were approached in a manner to reduce the frequency of failure; mitigate the effects of failure; alleviate the circumstances in which failures occur; and mitigate the consequence of accidents. The RCO will be linked to the hazards in the evaluation process [15].

Step 4, for cost benefit assessment, a survey is conducted to determine the conceptual benefit against the cost of each of the proposed counter measures for hazards on Kenyir Lake based on a scale of values of estimated benefit and cost [9]. A closed ended questionnaire is used where the respondent will assign the perceived value of estimated benefit and cost of the proposed counter measure. The selected perceived assign values are then calculated to obtain the average based on the formula:

$$
C B A_{A B}=\frac{\sum A B_{(1+2+3+\cdots, n)}}{n}
$$

Where $C B A_{A B}$ is the perceived value of aids to navigation benefit, $\sum A B_{(1+2+3+\cdots . n)}$ is the sum of all perceived values of aids to navigation and $n$ is the total number of respondent [14].

The cost and benefit perceived value data of each counter measure is then further analysed to arrive at its Benefit Cost Ratio (BCR) value using the formula:

$$
B C R_{C M}=\frac{\sum B_{C M}}{\sum C_{C M}}
$$

Where $B C R_{C M}$ is the benefit cost ratio of value for the counter measure, $\sum B_{C M}$ is sum of all the value of benefits and $\sum C_{C M}$ is the sum of all value of cost for this counter measure. If the outcome of BCR for a counter measure is more than 1.0 then the benefits exceeds the cost and it is recommended, if it less than 1.0 then its cost exceeds benefits and thus not recommended [15].

$\underline{\text { Step 5 }}$, recommendations will be based upon the comparison and ranking of all hazards and their underlying causes, the comparison and ranking of counter measures as a function of associated costs and benefits and the identification of those counter measures which keep risks as low as reasonably practicable.

\section{Findings}

Step 1, HAZID consultation, discussion and survey were carried out to select the most pertinent hazards based on the unique environment and current navigation practices on Kenyir Lake, the outcome of this engagement is listed in Table IV. Five hazards labelled H1 to H5 were identified to be the most relevant hazards on navigation on Kenyir Lake. 
Table 4: Expert Identification on Hazards for Kenyir Lake

\begin{tabular}{|c|l|l|}
\hline ID & \multicolumn{1}{|c|}{ Hazard } & \multicolumn{1}{c|}{ Justification } \\
\hline H1 & Collision & $\begin{array}{l}\text { High probability due to increasing number of vessels on } \\
\text { Kenyir Lake. }\end{array}$ \\
\hline H2 & Grounding & $\begin{array}{l}\text { High probability due to submerged shallows, drying } \\
\text { stumps, rocks and changing water levels. }\end{array}$ \\
\hline H3 & Getting Lost & $\begin{array}{l}\text { High probability due to the lush foliage surrounding the } \\
\text { lake. }\end{array}$ \\
\hline H4 & Man Overboard & High probability due to activities practised. \\
\hline H5 & Capsizing & $\begin{array}{l}\text { High probability due to underwater features or sudden } \\
\text { wind gusts. }\end{array}$ \\
\hline
\end{tabular}

Step 2, risk analysis was conducted using pair wise comparison method where a $5 \mathrm{x} 5$ pair-wise comparison matrix was developed for obtaining the weight of each criteria. A (H1, H2, H3, H4, H5) matrix expressing the qualified judgement with regard to the relative priority of collision (H1), grounding (H2), getting lost (H3), man overboard (H4) and capsizing (H5), Table V. The expert's numerical assessment based on its corresponding linguistic meaning is used to construct the matrix. The qualified judgements on pairs of attribute $H_{i}$ and $H_{j}$ are represented by a $n \times n$ matrix $\mathrm{A}$. The entries $h_{i j}$ are defined by the following entry rules [11]:

Rule 1. If $h_{i j}=\alpha$, then $h_{j i}=1 / \alpha, \alpha \neq 0$;

Rule 2. If $H_{i}$ is judged to be equal relative importance as $H_{j}$, then $h_{i j}=h_{j i}=1$.

Table 5: Pair-Wise Comparison Matrix for the Main Criteria

\begin{tabular}{|c|c|c|c|c|c|}
\hline & H1 & H2 & H3 & H4 & H5 \\
\hline H1 & 1 & 0.350119 & 0.458631 & 0.634484 & 0.246885 \\
\hline H2 & 2.856171 & 1 & 0.456349 & 0.401032 & 0.292361 \\
\hline H3 & 2.180402 & 2.1913044 & 1 & 0.258056 & 0.381528 \\
\hline H4 & 1.576084 & 2.493568 & 3.875135 & 1 & 0.332202 \\
\hline H5 & 4.050470 & 3.420428 & 2.621041 & 3.010213 & 1 \\
\hline SUM & $\mathbf{1 1 . 6 6 3 1 2 7}$ & $\mathbf{9 . 4 5 5 4 1 9}$ & $\mathbf{8 . 4 1 1 1 5 5}$ & $\mathbf{5 . 3 0 3 7 8 4}$ & $\mathbf{2 . 2 5 2 9 7 6}$ \\
\hline
\end{tabular}

The performance ratio of $A(H 1, H 2, H 3, H 4, H 5)$ is then calculated as follows, Table 6.

Table 6: Performance Ratio of Each Main Criteria

\begin{tabular}{|c|c|c|c|c|c|}
\hline & $1 \div$ & $0.350119 \div$ & $0.458631 \div$ & $0.634484 \div$ & $0.246885 \div$ \\
H1 & $11.663127=$ & $9.455419=$ & $8.411155=$ & $5.303784=$ & $2.252976=$ \\
& 0.085740 & 0.037028 & 0.054526 & 0.119628 & 0.109581 \\
\hline H2 & 0.244888 & 0.105759 & 0.054255 & 0.075612 & 0.129766 \\
\hline H3 & 0.186948 & 0.231751 & 0.118889 & 0.048654 & 0.169343 \\
\hline H4 & 0.135133 & 0.263718 & 0.460713 & 0.188544 & 0.147450 \\
\hline H5 & 0.347288 & 0.361742 & 0.311614 & 0.567559 & 0.443857 \\
\hline
\end{tabular}

The weight values of all main criteria are determined as follows; given the criterion ' $\mathrm{H} 1$ ' as an example, the weight value is computed as 


$$
\mathrm{W}^{\mathrm{H} 1}=(0.085740+0.037028+0.054526+0.119628+0.109581) \div 5=0.081301 \text {. }
$$

Where the weight value of the criterion H1 is known to be 0.081301 . Similarly, the weight calculation algorithm is applied to all other criteria and the output value of the weight calculation is summarised in Table 7 where $\mathrm{W}^{\mathrm{H}}$ is the weight value of the hazard.

Table 7: Weight Value of Evaluation Main Criteria

\begin{tabular}{|l|c|}
\hline & Weight Value $\left(\mathbf{W}^{\mathbf{H}}\right.$...) \\
\hline H1 & 0.081301 \\
\hline H2 & 0.122056 \\
\hline H3 & 0.151117 \\
\hline H4 & 0.239112 \\
\hline H5 & 0.406412 \\
\hline
\end{tabular}

Next, the calculation of the CR of the pair-wise comparison is conducted. Each value in the column of the pair-wise comparison matrix from Table $\mathrm{V}$ is multiplied by the weight value of each criterion from Table VII. The output of the calculation process of consistency ratio of pair-wise comparison is summarised in Table 8.

Table 8: The Total Value of the Calculation

\begin{tabular}{|c|c|}
\hline & Total \\
\hline H1 & 0.445392 \\
\hline H2 & 0.637939 \\
\hline H3 & 0.812611 \\
\hline H4 & 1.392218 \\
\hline H5 & 2.269069 \\
\hline
\end{tabular}

To calculate the $\frac{\sum_{k=1}^{n} w_{k} a_{j k}}{w_{i}}$ value as mentioned in Step 2, the total value of each main criterion described in Table VIII must be divided with the weight value of the corresponding main criteria as follows:

$$
\begin{array}{r}
\frac{0.445392}{0.08130}=5.478311 ; \frac{0.637939}{0.122056}=5.226591 ; \\
\frac{0.812611}{0.151117}=5.377345 ; \frac{1.392218}{0.239112}=5.822447 ; \frac{2.269069}{0.406412}=5.583169
\end{array}
$$

The $\lambda_{\max }$ is then calculated as follows:

$$
\lambda_{\max }=\frac{5.478311+5.226591+5.377345+5.822447+5.583169}{5}=5.497573
$$

Next, the $C I$ is computed as follows:

$$
C I=\frac{5.497573-5}{5-1}=0.124393
$$

Subsequently, the consistency ratio $(C R)$ is calculated using equation (1). There are 5 criteria therefore the random index $(R I)$ is 1.12 , Table 9 , and the $C R$ value of the main criteria is found as follows [12]:

$$
C R=\frac{0.124393}{1.12}=0.111065
$$


Table 9: Random Index (RI)

\begin{tabular}{|c|c|c|c|c|c|c|c|c|c|c|}
\hline$n$ & 1 & 2 & 3 & 4 & $\mathbf{5}$ & 6 & 7 & 8 & 9 & 10 \\
\hline $\boldsymbol{R I}$ & 0 & 0 & 0.58 & 0.9 & $\mathbf{1 . 1 2}$ & 1.24 & 1.32 & 1.41 & 1.45 & 1.49 \\
\hline \multicolumn{8}{c|}{ Source: Saaty, 2008. }
\end{tabular}

The final calculation with a consistency ratio of 0.111065 yield an assessment grade of the hazards. This is very close to the accepted degree of consistency that is 0.10 in a pair-wise comparison calculation. Business Performance Management Singapore (BPMSG) suggests accepting CR $>10 \%$, practically up to $20 \%$, depending on the nature and objective. It is argued that it has to do with the human limits on the capacity for processing information, which was originally published by George A. Miller in 1956, and then taken up by Saaty and Ozdemir in a publication in 2003 [16].

Based on this, the consistency of the pair-wise comparisons is considered reasonable. Qualitative data with five number of grades and the weight value of each grade is shown in Table 10.

Table 10: Assessment Grade of Navigation Hazard at Kenyir Lake

\begin{tabular}{|c|c|c|}
\hline ID & Hazard & Value \\
\hline H5 & Capsizing & 2.269069 \\
\hline H4 & Man Overboard & 1.392218 \\
\hline H3 & Getting Lost & 0.812611 \\
\hline H2 & Grounding & 0.637939 \\
\hline H1 & Collision & 0.445392 \\
\hline
\end{tabular}

H5, hazard of capsizing has the highest value and is acknowledged to be the primary hazard at Kenyir Lake. According to the experts, these incidents are rare, but it does happen resulting in total loss of vessels which may inevitably sank in waters up to 200 meters deep.

$\underline{\text { Step 3 }}$, RCO aims to reduce the frequency of failure; mitigate the effects of failure; alleviate the circumstances in which failures occur; and mitigate the consequence of accidents [17]. A list of safety tools associated with navigation was produced for consideration and discussion with experts to determine which could be used as counter measures for the identified hazards of Kenyir Lake [4], Table 11.

Table 11: Proposed Counter Measures for Kenyir Lake Hazards

\begin{tabular}{|l|l|l|}
\hline & Counter measure & Expected functions \\
\hline $\mathbf{1}$ & AtoNs & $\begin{array}{l}\text { Aids to navigation to provide guidance, directional } \\
\text { and markers for points of interest. }\end{array}$ \\
\hline $\mathbf{2}$ & Routeing system & $\begin{array}{l}\text { Marked routes to and from points of interest with } \\
\text { specific traffic flow direction and separation. }\end{array}$ \\
\hline $\mathbf{3}$ & $\begin{array}{l}\text { Communications } \\
\text { Eqp. }\end{array}$ & $\begin{array}{l}\text { To mitigate the lack of mobile signal in the lake } \\
\text { areas. }\end{array}$ \\
\hline $\mathbf{4}$ & Designated shelter & $\begin{array}{l}\text { To provide shelter in cases where boats are unable } \\
\text { to navigate back due to weather or timing. }\end{array}$ \\
\hline $\mathbf{5}$ & SOP & $\begin{array}{l}\text { To provide a comprehensive standard operating } \\
\text { procedure for navigation in Kenyir Lake. }\end{array}$ \\
\hline
\end{tabular}

Source: Osnin et al., 2017

Step 4, a cost benefit assessment was then conducted to determine the conceptual benefit against the cost of each of the proposed counter measures for hazards at Kenyir Lake. This is to identify and 
compare benefits and costs associated with the implementation of each identified counter measure which are based on estimate of benefit and cost. A community survey on the conceptual benefit against cost of counter measures for navigation hazards in Kenyir Lake is conducted and the perceived average value was calculated using equation (2). Since the study is focused on navigation, the sample size was determined based on the population of vessels used on Kenyir Lake. The population and sample size of the data was based on the number of registered vessels plus estimated number of unregistered vessels provided by the authority, Table I. Since vessels are inanimate objects that merely float on water, the local community will be engaged as respondent for this study. Constructed on the number of boats estimated at 260, according to Krejcie and Morgan the sample size would be $155[18]$.

However, most of these boats were left abandoned when not in use. Due to limitation of time and resources a final 92 sample were used for this survey. The outcome of the cost benefit assessment is presented in Figure 3 which illustrates the estimate of benefit against the estimate of cost for each of the proposed counter measures.

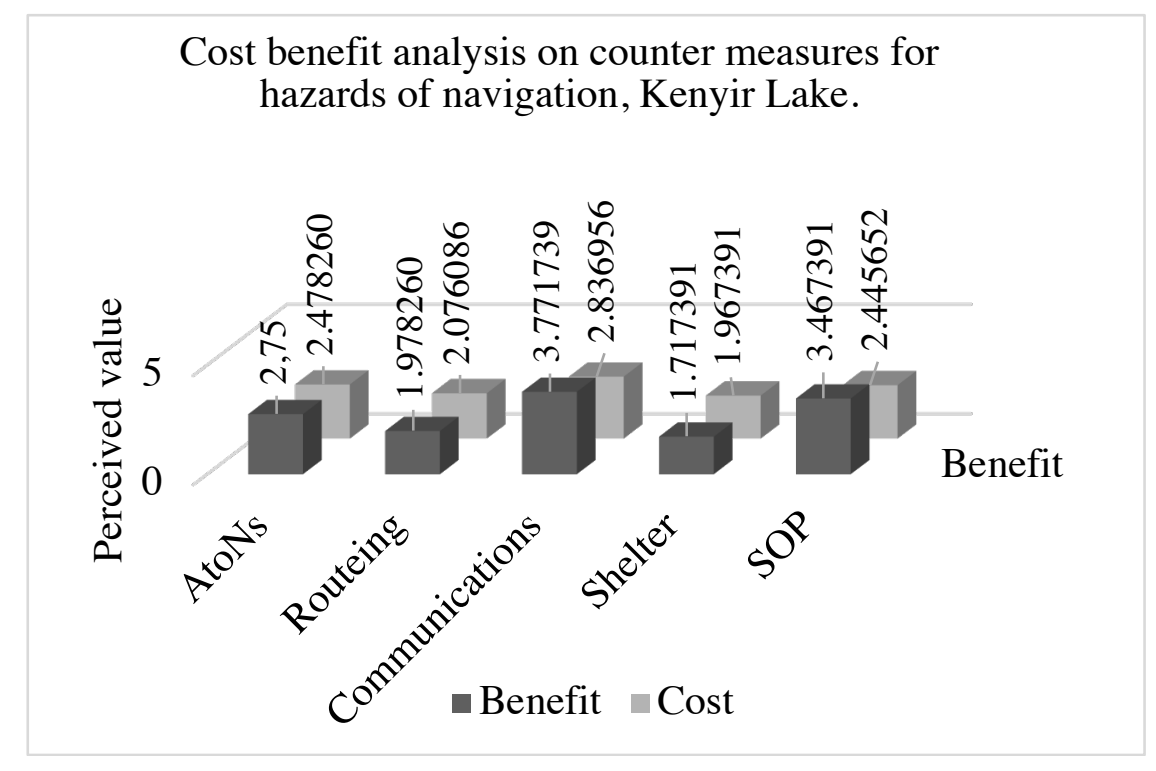

Figure 4. Analysis for Counter Measures

The cost benefit data of each counter measure is then further analysed to determine its Benefit Cost Ratio (BCR) using equation (3). A BCR of more than 1.0 is a positive indication of the proposed counter measure. The outcome of this calculation is summarized in Figure 4. 


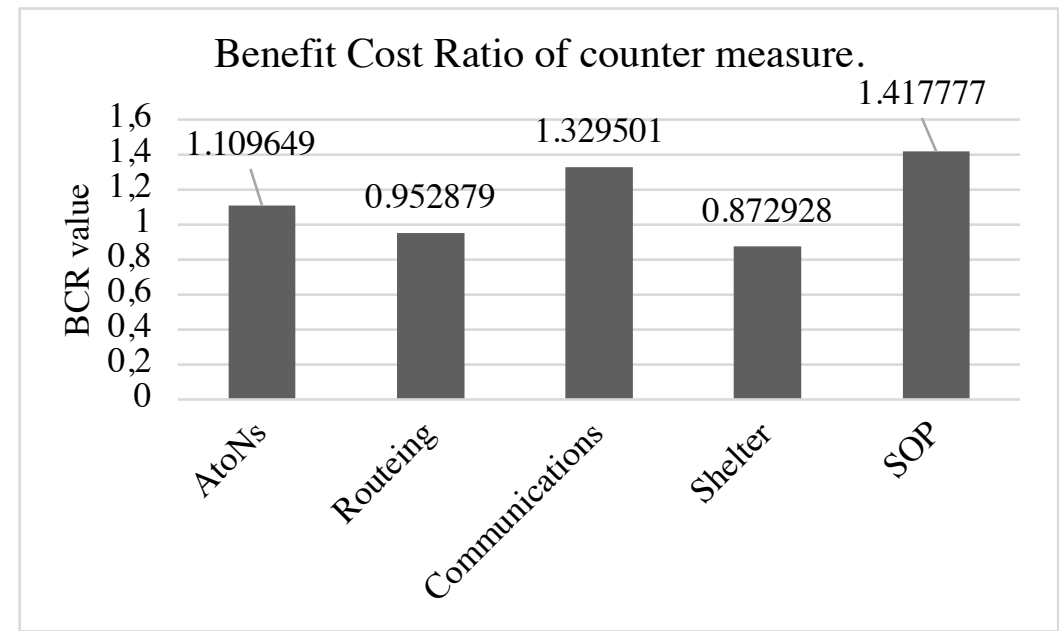

Figure 4: Analysis for BCR

Standard operating procedures has the highest BCR at 1.4 followed by communications equipment at 1.3 , AtoNs at 1.1 , routeing at 0.9 with designated shelter having the lowest BCR at 0.8.

Step 5, recommendations are based on the comparison and ranking of identified hazards and their underlying causes, the comparison and ranking of counter measures as a function of associated costs and benefits and the identification of those counter measures which keep risks as low as reasonably practicable.

The main hazard on current navigation practices at Kenyir Lake was of capsizing and man overboard while the control measures with highest benefit cost ratio (BCR) is standard operating procedures followed by communications equipment.

\section{Discussion and Conclusion}

Kenyir Lake is a key tourist destination with gradually increasing number of visitor's year on year. There is substantial lake use either for mode of transport, leisure activities and for income generation. Grounded on observations, expert opinion and community survey it was established that the use of boats and navigation play a core role on Kenyir Lake. A safe marine environment and navigational safety is therefore essential in protecting the benefits of Kenyir Lake as a major tourist destination. Navigational safety will also lead to a more efficient transport system and be beneficial to the tourism industry.

Existing navigation system as applied is based on the most rudimentary of human faculties that is by sight and hearing which leads to an inherent limitation as travel over water can only be done during daylight hours and navigating the lake requires native familiarity. The research limitation faced are lack of official data on navigation accidents, record of incidences or even journal papers on the subject matter. Based on available information and primary data, the FSA method was applied on current navigation practices of Kenyir Lake. The study identified hazards on navigation in Kenyir Lake and proposes control measures to ensure navigational safety of users. It was learned that the main hazard of Kenyir Lake was of capsizing and man overboard while the control measures with highest benefit cost ratio is standard operating procedures followed by communications. Based on the outcome of this findings, the next step would be to develop a framework of navigation system Kenyir Lake in accordance with accepted standards and convention that are applied elsewhere in Malaysia. This would provide a systematic approach to lake use and ultimately have positive implication for holistic development of Kenyir Lake as a major tourist destination. The contribution of this study is listed in Table 12. 
Table 12: Theoretical and Managerial Contribution

\begin{tabular}{|c|c|l|}
\hline \multirow{2}{*}{$\begin{array}{c}\text { Theoretical } \\
\text { Contribution }\end{array}$} & 1 & $\begin{array}{l}\text { The FSA approach combined with community survey seems practical in } \\
\text { ranking of hazards and selecting the priority of counter measures for Kenyir } \\
\text { Lake. }\end{array}$ \\
\cline { 2 - 3 } Managerial & 2 & $\begin{array}{l}\text { The FSA approach could be a primary method for assessing navigation in } \\
\text { inland or enclosed water. }\end{array}$ \\
\cline { 2 - 4 } $\begin{array}{c}\text { Contribution } \\
\text { Mation }\end{array}$ & 1 & $\begin{array}{l}\text { Local Authority, Associations and other vested parties could take this } \\
\text { approach to enhance navigational safety practices on inland navigation. }\end{array}$ \\
\hline $\begin{array}{l}\text { Terengganu Tourism Department and The Ministry of Tourism and Culture } \\
\text { Malaysia in general will benefit from this study as Kenyir Lake is a local } \\
\text { and globally attractive tourism destination with various national and } \\
\text { international events such as fishing competition, international triathlons, } \\
\text { etc. }\end{array}$ \\
\hline
\end{tabular}

\section{Acknowledgement}

The authors would like to thank the Central Terengganu Development Authority, the Hulu Terengganu District Council, Universiti Malaysia Terengganu, the experts, local community, research assistants and all those who provided cooperation and assistance for this study.

\section{References}

[1] IMO, "Focus on IMO, IMO and the Safety of Navigation", International Maritime Organisation, London, 1998.

[2] Mohd Sharoum, Faizah, Mohd Tajuddin Abdullah, Che Aziz Ali, and Roslina Ismail. "Geopark Tasik Kenyir". Penerbit Universiti Malaysia Terengganu. Terengganu, Malaysia, 2015.

[3] FARLEX, "Inland Waters". Accessed 22 December 2017. https://legaldictionary.thefreedictionary.com/Inland + Waters

[4] Osnin NA, Abdul Rahman NSF and Ahmad Fuad AF, “A Study of Navigation System at Kenyir Lake to Safeguard Societal Wellbeing”. Kuala Terengganu. Global Tourism Conference, July 2017.

[5] KETENGAH." Tasik Kenyir Tourism Information”. Accessed 10 February 2016. http://www.ketengah.gov.my/

[6] UPEN, State Economic Planning Unit. "Terengganu Basic Data 2015”. Kuala Terengganu, Malaysia, 2015.

[7] MDHT. “Boat License Registry Kenyir Lake 01/01/2017”. Kuala Terengganu, Malaysia. 2018.

[8] Marine Department Malaysia, "Quality Policy", Accessed 16 January 2018, http://www.marine.gov.my/jlmeng/Contentdetail.asp?article_id=233\&category_id $=2 \&$ subcategory_id=3\&subcat egory $2 i d=0$

[9] IMO. "MSC/Circ. 1023. Guidelines for Formal Safety Assessment (FSA) For Use in The Imo Rule-Making Process". International Maritime Organisation, London, 2002.

[10] IMO, "FSA and Method of Work". Submitted by the International Association of Classification Societies (IACS). MSC 94/13/1. International Maritime Organisation, London, 2014.

[11] Abdul Rahman, N.S.F. and Ahmad Najib, A.F. "Selection of the Most Practical Malaysian Port for Enhancing the Malaysia-China Kuantan Industrial Park Business Trade”. Int. J. Shipping and Transport Logistics, Vol.9, No. 4, pp. 500-525, 2017.

[12] Saaty, T.L., "Decision Making with the Analytic Hierarchy Process”. International Journal Services Sciences, Vol. 1 No.1: 87-98, 2008.

[13] Piotr Kopacz, "On Improper Implementation of Formal Safety Assessment in Practice”. Gdynia Maritime University. Gdynia, 2014.

[14] Allen, Elaine and Seaman, Christopher, "Likert Scales and Data Analyses". Quality Progress. 2007.

[15] UMN, "Cost Benefit Analysis Methodology". University of Minnesota. Accessed 19 June 2017. http://www.isye.umn.edu/courses/ie5441/pdf/Notes_9.pdf pp. 64-65

[16] BPMSG, "AHP High Consistency Ratio". Accessed 12 June 2017. http://bpmsg.com/ahp-high-consistency-ratio/

[17] IACS, "Formal Safety Assessment Overview”. Maritime Safety Committee 75th Session. London, 2002. Krejcie \& Morgan, "Determining sample size for research activities. Educational and psychological measurement", 30, 607610,1970 